\title{
The role of self-serving cognitive distortions in reactive and proactive aggression
}

S. Oostermeijer ${ }^{1}$, K.C. Smeets ${ }^{2}$, L.M.C. Jansen ${ }^{1}$, T. Jambroes ${ }^{1}$, N.N.J. Rommelse ${ }^{2,6}$, F.E. Scheepers ${ }^{4}$, J.K.

Buitelaar $^{2,3}$, A. Popma ${ }^{1,5}$

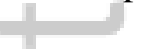

${ }^{1}$ VUmc, Department of Child- and Adolescent Psychiatry, Amsterdam, The Netherlands

${ }^{2}$ Karakter Child- and Adolescent Psychiatry, Nijmegen, The Netherlands

${ }^{3}$ Radboud University Medical Centre, Donders Institute for Brain, Cognition and Behaviour, Department of Cognitive Neuroscience, Nijmegen, The Netherlands;

${ }^{4}$ UMC Utrecht, Rudolf Magnus Institute of Neuroscience, Department of Psychiatry, Utrecht, The Netherlands

${ }^{5}$ Leiden University, Institute of Criminal Law \& Criminology, Leiden, The Netherlands

${ }^{6}$ Radboud University Medical Centre, Donders Institute for Brain, Cognition and Behaviour, Department of Psychiatry, Nijmegen, The Netherlands

Correspondence to:

S. Oostermeijer, department of Child- and Adolescent Psychiatry VUMC Amsterdam, Rijksstraatweg 145, 1115 ZG Duivendrecht, The Netherlands. Phone number: 003120 891545. Email: s.oostermeijer@debascule.com

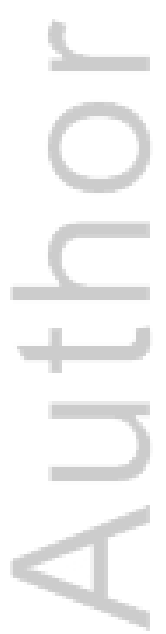

This is the author manuscript accepted for publication and has undergone full peer review but has not been through the copyediting, typesetting, pagination and proofreading process, which may lead to differences between this version and the Version of Record. Please cite this article as doi: $10.1002 / \mathrm{cbm} .2039$

This article is protected by copyright. All rights reserved. 


\begin{abstract}
Background. Aggression is often divided into reactive and proactive forms. Reactive aggression is typically thought to encompass 'blaming others' and 'assuming the worst', while proactive aggression relates to 'selfcenteredness' and 'minimizing/mislabelling'.
\end{abstract}

Aim. Our aim was to evaluate relationships between reactive and proactive aggression and cognitive distortions and to test whether changes in these cognitions relate to changes in aggression.

Methods. 151 adolescents (60\% boys; mean age 15.05 years, standard deviation 1.28) were enrolled in an evidence-based intervention to reduce aggression. Due to attrition and anomalous responses the postintervention sample involved 80 adolescents. Correlation and linear regression analyses were used to investigate the relationship between cognitive distortions and aggression.

Results. Blaming others was related to reactive aggression before the intervention, while all cognitive distortions were related to proactive aggression both pre- and post-intervention. Changes in reactive aggression were uniquely predicted by blaming others, while changes in proactive aggression were predicted by changes in cognitive distortions overall.

Conclusion. To our knowledge this study is the first to show a relationship between changes in cognitive distortions and changes in aggression. Treatment of reactive aggression may benefit from focusing primarily on reducing cognitive distortions involving misattribution of blame to others.

Keywords. reactive aggression; proactive aggression; cognitive distortions; intervention, behavioural changes 
Aggression is a heterogeneous concept for which various distinctions have been proposed (Anderson \& Huesmann, 2003). A common approach is to subdivide aggression based on function or motive; defensive aggression, often labelled as reactive aggression is distinguished from instrumental aggression, also known as proactive aggression (Vitiello \& Stoff, 1997). Literature has shown that despite high correlations between reactive and proactive aggression these subtypes also have specific correlates such as peer status, biological measures and social information processing (Kempes et al., 2005). The Social Information Processing (SIP) model (Crick \& Dodge, 1994) assumes that aggression originates from problems in social information processing. Division into reactive and proactive aggression seems particularly promising for understanding aetiology. Reactive aggression involves hostile attributions and is often frustration based, while proactive aggression stems from positive outcome learning (Merk et al., 2005). The SIP model assumes that, in a social situation, behaviour is achieved through six sequential steps (see Crick \& Dodge, 1994). Reactive aggression is thought to relate uniquely to difficulties in encoding and interpreting cues, whilst proactive aggression is thought to relate to positive expectancies from aggression, such as personal gain consequent upon it (Crick \& Dodge, 1994, 1996). Hostile attribution style or bias (HAS) is the tendency to attribute hostile intent to others and, as such, involves encoding and interpreting cues. Reactive aggression has been linked to HAS in adults (Lobbestael et al., 2013) and young children (de Castro et al., 2005). Proactive aggression has been shown to relate uniquely to biased response evaluation in young children (de Castro et al., 2005) and detained girls (Marsee \& Frick, 2007). More recently it has been shown that presumed early and late steps in the process are involved in both reactive and proactive aggression, with self-rated competency and positive evaluation 
relating to reactive aggression in severely antisocial adolescents, and proactive aggression to 'overlooking consequences' (Oostermeijer et al., 2016). Reactive and proactive aggression may, thus, involve distinct SIP problems.

Social information processing is influenced by stored memories and past experiences (Crick \& Dodge, 1994). In this regard social cognitions, specifically 'self-serving' cognitive distortions, are thought to contribute to harmful acts against others and are thus linked to aggression (Barriga et al., 2008, 2000). Such cognitions protect the self from developing a negative self-image, push the blame away from oneself, and promote harmful acts towards others. Four categories have been identified (Barriga \& Gibbs, 1996; Gibb et al., 2001) which are considered as interrelated constructs, which may be further divided into primary (SC) and secondary distortions ( $\mathrm{BO}, \mathrm{MM}$ and $\mathrm{AW})$; secondary cognitive distortions are thought to support selfcenteredness and prevent damage to the self-image. The four main categories are: self-centredness (SC), blaming others (BO) minimizing/mislabelling (MM) and assuming the worst (AW). Self-centredness involves according status to one's own views, expectations, needs, rights, immediate feelings, and desires to such a degree that the legitimate views of others are rarely considered, or are disregarded altogether. This fits with pursuit of personal gain, specifically thought to play a role in proactive aggression. Proactive aggression has, however, also been linked to biased response evaluation and fewer relationship endorsing goals (Crick \& Dodge, 1996). In this regard, minimizing/mislabelling involves depicting antisocial behaviour as causing no real harm to others and even as acceptable or admirable; others may be belittled or dehumanized. Reactive aggression, by contrast, has been characterized by perceived threat and defensiveness (Merk et al., 2005), which fits well with the cognitive distortion of blaming others, itself, in turn, linked with reactive aggression (Koolen et al., 2012). 'Assuming the worst' amounts to gratuitous attribution of hostile intentions to others, considering a worst-case scenario for a social situation as if it were inevitable, or assuming that improvement is impossible in one's own or another's behaviour. This directly relates to hostile attribution style, implicated in reactive aggression, which possibly fosters the use of aggression as a defence mechanism. Figure 1 offers a 
visual representation of the relationships described between the social information processing (SIP) steps, the two main forms of aggression (RA \& PA) and the hostile attributions or self-serving cognitive distortions (adjusted from Crick \& Dodge, 1994).

\author{
Figure 1 about here
}

To our knowledge no other studies have directly investigated relationships between cognitive distortions and reactive or proactive aggression, nor fully explored the effect of gender on any such relationships. Although differences between girls/women and boys/men have been shown in physiological and temperamental variables (Berkout et al., 2011), previous literature has shown no differences between them in cognitive distortions- antisocial behaviour relationships; nevertheless, it has been shown that adolescent girls tend to have a fewer cognitive distortions and less antisocial behaviour (Barriga et al., 2001). Similarly, when studying reactive and proactive aggression per se gender differences have been shown (Connor et al., 2003).

Promising treatments for antisocial behaviours involve cognitive-behavioural interventions (Lipsey et al., 2007). A meta-analysis has shown that cognitive-behavioural interventions have a medium effect size on reducing aggression in adolescents, however predictors of treatment outcomes seem unclear (Smeets et al., 2015). Only two of the 25 studies included in the review examined proactive and reactive aggression as a moderator of treatment outcome, and no effect of subtyping of aggression was reported. Typically these interventions aim to produce changes in cognition, feelings and behaviour (Kendall, 2011), targeting cognitive (antisocial) biases, beliefs, attributions and schemata's to change problem behaviour. Such social-cognitive structures influence and mediate decision-making processes, connecting external situations to the outcome of social or antisocial behaviour (Huesmann, 1998). It remains unclear whether changes in distinct social cognitions are associated with behavioural changes in reactive and proactive aggression. In order to give 
indications for more tailored treatment or provide specific treatment targets for reactive versus proactive aggression longitudinal research is needed.

Our main research questions were: 1) Are reactive and proactive aggression differentially related to the different types of self-serving cognitive distortions? 2) Are changes in these cognitions after treatment related to changes in reactive and proactive aggression? Our hypotheses were that reactive aggression is typically related to blaming others and assuming the worst, while proactive aggression is typically related to selfcentredness and minimising/mislabelling (see Figure 1) and this will hold true in measures of change.

\section{Methods}

\section{Participants}

All adolescents from a special school in Rotterdam for children with disruptive behavioural problems and from a residential facility for severe behavioural problems in Amsterdam who had displayed varying levels of aggression and were enrolled in an evidence-based intervention aimed at reducing this were considered eligible, and approached. The intervention was offered as part of standard treatment at the special school. Adolescents from the residential facility were referred by a health care professional. Written informed consent was obtained from every participant and parents or caregivers before enrolment in the study. Both studies were approved by the local Dutch ethical committee, CMO Arnhem/Nijmegen (registration number 2010/073, ABR number: NL 33231.091.10) and VUMC Amsterdam (registration number 2002/178, ABR number NL28476.029.09).

Participants were asked to fill in self-report questionnaires on aggression and self-serving cognitive distortions pre- and post-intervention. The How I Think (HIT) questionnaire used in our study provides an Anomalous Responding (AR) score. Participants with an AR score above 5.00 were excluded from the analysis (Nas et al., 2008) to ensure reliable responses. 


\section{Measures}

Intelligence

Participants' intelligence quotient (IQ) scores were taken from records; measures included Wechsler Intelligence Scale for Children (WISC) and the WAIS Wechsler Adult Intelligence Scale.

\section{Reactive and proactive aggression}

The Reactive and Proactive Questionnaire (RPQ) was used to measure reactive and proactive aggression (Raine et al., 2006); this has been validated in a Dutch sample (Cima et al., 2013). The RPQ is a self-report questionnaire consisting of 23 items, with a three-point Likert scale: 'never' (0), 'sometimes' (1) or 'often' (2). Total RPQ aggression score may thus be calculated, as well as a reactive aggression score ([RA], 12 items) and a proactive aggression score ([PA], 11 items). The RPQ has shown good internal reliability for total aggression and the two subscales (Raine et al., 2006).

\section{Cognitive distortions}

Self-serving cognitive distortions were assessed with the Dutch translation of the How I Think Questionnaire ([HIT] Nas et al., 2008). This has 54 items, rated on a five-point scale from 'I strongly disagree' (0) to 'I strongly agree' (5). A few items are included to act as positive fillers and persuade the participant to use the full range of the scale. Test-retest reliability and internal reliability of the HIT have been reported as high (Barriga \& Gibbs, 1996). This has also been shown in a Dutch validation study (Nas et al., 2008).

\section{Aggression replacement training}

All adolescents included were enrolled in aggression replacement training, a cognitive behavioural intervention aimed at reducing aggressive and delinquent behaviours through improving social skills, promoting anger management and boosting moral reasoning, simultaneously (Goldstein et al., 1998). There 
are 30 hour- long sessions in total, one delivered three times per week. Research has shown positive results for aggressive and delinquent populations (Goldstein et al., 1994; Gundersen \& Svartdal, 2006; Hatcher et al., 2008). It should be noted this intervention is evidence-based, and assessing treatment integrity or treatment effect was not the aim of the current study. Rather, we were concerned only with the relationship between cognitive distortions and behavioural change.

\section{Statistical analyses}

Cronbach's Alpha's for both the HIT and RPQ questionnaire subscales were calculated to check reliability. First, to examine whether reactive and proactive aggression each showed unique correlations with the HIT subscales, Spearman's rank-order correlations were calculated (due to non-parametric data of the proactive aggression scale post-intervention) together with partial correlation to correct for shared variance.

To examine the relationship between the cognitive behavioural intervention and change, we investigated whether the RPQ and HIT scales differed at pre- (T1) and post-intervention (T2), using paired samples t-tests. A Wilcoxon Signed Rank test for non-parametric data was performed on proactive aggression scores. Dropouts (participant without post-intervention data) were compared with participants with complete data on pre-intervention HIT and RPQ scores. Finally, linear regression analyses were used to investigate whether HIT subscale difference-scores (T2-T1) could predict difference-scores (T2-T1) on the RPQ subscales. Difference-scores were considered reliable variables for analysis, with pre- and post-intervention scores being sufficiently correlated (Pearson's $r>0.50$, with an exception of HIT-SC with $r=0.498$ ). Multicollinearity statistics were investigated to assess whether intercorrelation between the subscales could cause potential biases. Post hoc analyses were performed to allow for gender, which was added to the linear regression analysis as a covariate. 


\section{Results}

One hundred and fifty-one participants were included in the pre-intervention correlation analysis (Table 1, figure 2). Data were checked for outliers (2 SD from the mean), which resulted in exclusion of one participant (outlier for HIT total and 3 HIT subscales). After study drop outs (n=53) and anomalous post-intervention responses $(n=16)$, a group of 80 participants had both pre- and post-intervention scores (Table 1).

[Insert Table 1 and Figure 2 about here]

The pre- and post-intervention Cronbach's alphas for the HIT subscales ranged from 0.764 (BO) to 0.836 (AW) for pre-intervention and from 0.785 (SC) to 0.813 (AW) post-intervention. For the RPQ subscales Cronbach's alphas varied between 0.874 (RA) and 0.883 (PA) pre-intervention and 0.870 (RA) and 0.880 (PA) post-intervention. Significant correlations between both reactive and proactive aggression at baseline (T1) and eh second interview (T2), and self-serving cognitions on all four HIT subscales were found (ranging from $r=0.304$ to $0.598, p<0.001$ ). Partial correlation results for reactive aggression (after correcting for PA) showed a significant correlation with the blaming others subscale of the HIT $(r=0.201, p<0.05)$ at T1 but no significant correlations at T2. Proactive aggression (when correcting for RA) showed significant correlations for both T1 and T2 with all HIT subscales (ranging from $r=0.282$ to $0.462, p<0.05$ ). Results of the paired sample t-tests are shown in Table 2 for all adolescents who completed a pre-intervention evaluation (T1 preintervention) and for all those who completed the intervention and a second measurement 'T2 postintervention'. Those who dropped out had significantly lower pre-intervention scores than participants with complete both $\mathrm{T} 1$ and $\mathrm{T} 2$ measurements (see Table 3). For the RPQ aggression scales no significant differences on RPQ total, RA or PA scales were found. 
[Insert Tables $2 \& 3$ about here]

Results of the regression analysis with reactive/proactive aggression as the dependent variable and HIT scales as independent variables are shown in Table 4. Multi-collinearity might bias results, but VIF values around 2.5 and Tolerance values above 0.3 do not raise much concern (Menard, 1995).

[Insert Table 4 about here]

When correcting for gender in the model for reactive aggression, an overall relationship with total cognitive distortion score is no longer significant $\left(F(5,71)=2.26, p=0.057, \mathrm{R}^{2}=0.138, \mathrm{R}_{\text {adjusted }}^{2}=0.077\right)$. When investigating cognitive distortion subscales separately, blaming others no longer had a unique contribution in predicting reactive aggression $(\beta=.275, t(76)=1.91, p=0.061)$. When correcting for gender in the proactive aggression model, the overall model remained significant $\left(F(5,72)=2.67, p<.05, \mathrm{R}^{2}=.156, \mathrm{R}_{\text {adjusted }}^{2}=0.098\right)$. When investigating the coefficients of the separate cognitive distortions, none of the individual cognitive distortions showed a relationship with aggression type in the gender adjusted model.

\section{Discussion}

We found that both types of aggression are related to self-serving cognitions, with no particular distinction between subtypes, according to correlation analysis. Partial correlations provided a measurement of association between the aggression subtypes and cognitive distortions in which variance explained by the other aggression scale was filtered out. These results indicated that higher reactive aggression before the intervention was uniquely correlated with blaming others, although a low correlation, while proactive 
aggression both pre- and post-intervention had low to moderate correlations with all four cognitive distortion subtypes. Blaming others typically involves misattributing blame to outside sources, so its distinctive relationship with reactive aggression fits with the latter being a defensive form of aggression (Merk et al., 2005). We did not, however, find the expected relationship between assuming the worst and reactive aggression. This is somewhat surprising, as blaming others has similarity to a hostile attribution style, and a link between this and reactive aggression has previously been demonstrated (de Castro et al., 2005; Lobbestael et al., 2013). Assuming the worst does, however, have connotations over and above hostile attributions as it involves cognitions related to 'worst-case scenarios' - as if a bad outcome were inevitable and entirely outside the control of the individual; this additional quality of hopelessness may limit action. Proactive aggression was related to all forms of cognitive biases. These self-serving cognitive biases are thought to protect the self from blame and negative self-concept (Barriga et al., 2000). Since proactive aggression is, by definition, premeditated, it may be more strongly related to a wide variety of cognitive biases than the more impulsive reactive aggression (Merk et al., 2005). Alternatively, our results could be explained by the severity of the aggression; proactive aggression is indicative of more serious harm (Smeets et al., 2016).

Our results confirmed that both reactive and proactive aggression, as well as self-serving cognitive distortions, showed significant decreases post intervention, although we do not claim this effect was necessarily solely attributable to the intervention. In this study there were two intervention settings, no control condition was available, and ratings were not blinded. Nevertheless, aggression replacement training is an evidence-based intervention that has proven to be effective in reducing aggression (Goldstein et al., 1994; Gundersen \& Svartdal, 2006; Hatcher et al., 2008). Our aim here was to examine associates of change, specifically potential cognitive correlates. Since attrition from this sample was high, we examined whether dropouts differed from the men retained on baseline aggression measures; they did not. They did, however, differ in their cognitive distortions. Those retained appeared to have fewer baseline cognitive distortions compared to the general population of adolescents enrolled in interventions for aggression. This could mean 
that those who experience more self-serving cognitive distortions have a higher tendency to drop out of cognitive behavioural treatments, and that additional support to sustain their attendance may be helpful. Where resources are exceptionally scarce, this finding could be used to help select those most likely to benefit.

With respect to our second question, our findings showed a relationship between total cognitive distortion change scores and changes in proactive aggression, but no relationship between change in any of the separate self-serving cognitions and changes in proactive aggression. By contrast, changes in blaming others were uniquely associated with behavioural change. Results were similar for both boys and girls. The latter fits with the findings of Barriga et al. (2001). In terms of the social information processing (SIP) model, this may suggest that reactive aggression is less likely to be a behavioural outcome if the individual's 'database' contains less mental structures involving misattribution of blame to outside sources, but cognitive biases collectively feed proactive aggression. Since this 'database' according to the SIP model is thought to influence all sequential steps reciprocally (Crick \& Dodge, 1994), changes in cognitive bias would have considerable on-going effects on future actions.

Limitations should be mentioned. There was a rather high dropout rate of 53 participants post-intervention (see figure 1), and drop-out was not random. Except for blaming others, participants without post-intervention data showed more self-serving cognitive distortions compared to participants with complete data. Our results, however, showed no difference in reactive and proactive aggression between the pre- and post-intervention group. The severity of cognitive distortions may serve as an indicator of risk for treatment drop-out. WE acknowledge that all measures included in young people wanted t present themselves rather than how they actually were. This potential problem was partly resolved by excluding participants with exceptionally high or anomalous responses on the HIT questionnaire. It has been suggested that sufficient at least average intelligence (IQ $\geq 90$ ) is needed for valid results on the HIT questionnaire (Nas et al., 2008), and this may also be true for other self-report questionnaires, (e.g. the RPQ), and for engaging in cognitive behavioural treatment. Unfortunately, we did not have IQ test results available for all in our sample, but generally 
adolescents thought to have below average IQ will not be enrolled in cognitive behavioural therapies, including the aggression regulation therapy.

To our knowledge this study is the first to investigate the relationship between changes in cognitive distortions and changes in aggressive behaviour. Treatment which focusses primarily on reducing the cognitive distortion of misattributing blame to others is likely to be most helpful in reducing reactive aggression, while it seems necessary to change self-serving cognitive distortions overall in order to reduce pro-active aggression. Future research is needed to assess whether it would actually be beneficial to tailor cognitive behavioural interventions in this way.

Acknowledgement. This study was funded by the National Initiative Brain \& Cognition (NIHC) (grant 056-24-014 \& 056-24-011) and Mental Health fund (Fonds Psychische Gezondheid) (grant 2008-6347).

Conflict of Interest: In the past 4 years, author J.K. Buitelaar has been a consultant to or member of the advisory board of and an occasional speaker for various pharmaceutical companies (fully disclosed to the editor), but none of these relate to this research. None of the other authors have any conflicts of interest to declare.

\section{References}

Anderson, C. A., \& Huesmann, L. R. (2003). Human Aggression: A Social-Cognitive View. The Sage Handbook of Social Psychology, 296-323.

Barriga, A. Q., \& Gibbs, J. C. (1996). Measuring cognitive distortion in antisocial youth: Development and preliminary validation of the "how I think" questionnaire. Aggressive Behavior, 22(5), 333-343. http://doi.org/10.1002/(SICI)1098-2337(1996)22:5<333::AID-AB2>3.0.CO;2-K

Barriga, A. Q., Hawkins, M. A., \& Camelia, C. R. T. (2008). Specificity of cognitive distortions to antisocial behaviours. Criminal Behaviour and Mental Health, 18(2), 104-116. http://doi.org/10.1002/cbm.683 
Barriga, A. Q., Landau, J. R., Stinson, B. L., Liau, A. K., \& Gibbs, J. C. (2000). Cognitive distortion and problem behaviors in adolescents. Criminal Justice and Behavior, 27(1), 36-56. http://doi.org/10.1177/0093854800027001003

Barriga, A. Q., Morrison, E. M., Liau, A. K., \& Gibbs, J. C. (2001). Moral Cognition: Explaining the Gender Difference in Antisocial Behavior. Merrill-Palmer Quarterly, 47(4), 532-562. http://doi.org/10.1353/mpq.2001.0020

Berkout, O. V., Young, J. N., \& Gross, A. M. (2011). Mean girls and bad boys: Recent research on gender differences in conduct disorder. Aggression and Violent Behavior, 16(6), 503-511. http://doi.org/10.1016/j.avb.2011.06.001

Cima, M., Raine, A., Meesters, C., \& Popma, A. (2013). Validation of the Dutch Reactive Proactive Questionnaire (RPQ): Differential Correlates of Reactive and Proactive Aggression From Childhood to Adulthood. Aggressive Behavior, 39(2), 99-113. http://doi.org/10.1002/ab.21458

Connor, D. F., Steingard, R. J., Anderson, J. J., \& Melloni, R. H. (2003). Gender Differences in Reactive and Proactive Aggression. Child Psychiatry and Human Development, 33(4), 279-294. http://doi.org/10.1023/A:1023084112561

Crick, N. R., \& Dodge, K. a. (1994). A review and reformulation of social information-processing mechanisms in children's social adjustment. Psychological Bulletin, 115(1), 74-101. http://doi.org/10.1037/0033-2909.115.1.74

Crick, N. R., \& Dodge, K. A. (1996). Social Information-Processing Mechanisms in Reactive and Proactive Aggression. Child Development, 67(3), 993-1002. http://doi.org/10.1111/j.1467-8624.1996.tb01778.x 
de Castro, B. O., Merk, W., Koops, W., Veerman, J. W., \& Bosch, J. D. (2005). Emotions in social information processing and their relations with reactive and proactive aggression in referred aggressive boys. Journal of Clinical Child and Adolescent Psychology, 34(1), 105-116.

http://doi.org/10.1207/s15374424jccp3401

Gibbs, J. C., Gibbs, P., Barriga, A. Q., \& Potter, G. B. (2001). How I Think Questionnaire and Manual. Research Press. Retrieved from https://books.google.com.au/books?id=72VFngEACAAJ

Goldstein, A. P., Glick, B., Carthan, W., \& Blancero, D. A. (1994). Prosocial gang: implementing aggression replacement training. Prosocial Gang: Implementing Aggression Replacement Training.

Goldstein, A. P., Glick, B., \& Gibbs, J. C. (1998). Aggression Replacement Training: A Comprehensive Intervention for Aggressive Youth (rev. ed). Adolescence (Vol. 33). http://doi.org/10.1016/01907409(88)90017-5

Gundersen, K., \& Svartdal, F. (2006). Aggression Replacement Training in Norway: Outcome evaluation of 11 Norwegian student projects. Scandinavian Journal of Educational Research, 50(1), 63-81. http://doi.org/10.1080/00313830500372059

Hatcher, R. M., Palmer, E. J., McGuire, J., Hounsome, J. C., Bilby, C. A. L., \& Hollin, C. R. (2008). Aggression replacement training with adult male offenders within community settings: a reconviction analysis. Journal of Forensic Psychiatry \& Psychology, 19(4), 517-532.

http://doi.org/10.1080/14789940801936407

Huesmann, L. R. (1998). The role of social information processing and cognitive schema in the acquisition and maintenance of habitual aggressive behavior. New York: Academic Press. 
Kempes, M., Matthys, W., de Vries, H., \& van Engeland, H. (2005). Reactive and proactive aggression in children--a review of theory, findings and the relevance for child and adolescent psychiatry. European Child \& Adolescent Psychiatry, 14(1), 11-9. http://doi.org/10.1007/s00787-005-0432-4

Kendall, P. C. (2011). Child and adolescent therapy: Cognitive-behavioral procedures. New York: The Guilford Press.

Koolen, S., Poorthuis, A., \& van Aken, M. A. G. (2012). Cognitive Distortions and Self-Regulatory Personality Traits Associated with Proactive and Reactive Aggression in Early Adolescence. Cognitive Therapy and Research, 36(6), 776-787. http://doi.org/10.1007/s10608-011-9407-6

Lipsey, M., Landenberger, N. A., \& Wilson, S. J. (2007). Effects of Cognitive-Behavioral Programs for Criminal Offenders: A Systematic Review. Campbell Systematic Reviews, 3(6).

Lobbestael, J., Cima, M., \& Arntz, A. (2013). The relationship between adult reactive and proactive aggression, hostile interpretation bias, and antisocial personality disorder. Journal of Personality Disorders, 27(1), 53-66. http://doi.org/10.1521/pedi.2013.27.1.53

Marsee, M. A., \& Frick, P. J. (2007). Exploring the cognitive and emotional correlates to proactive and reactive aggression in a sample of detained girls. Journal of Abnormal Child Psychology, 35(6), 969981. http://doi.org/10.1007/s10802-007-9147-y

Menard, S. (1995). Applied Logistic Regression Analysis (Vol. 106). Sage Publications, Thousand Oaks, California. http://doi.org/10.4135/9781412983433

Merk, W., de Castro, B. O., Koops, W., \& Matthys, W. (2005). The distinction between reactive and proactive aggression: Utility for theory, diagnosis and treatment? European Journal of Developmental Psychology, 
2(2), 197-220. http://doi.org/10.1080/17405620444000300

Nas, C. N., Brugman, D., \& Koops, W. (2008). Measuring self-serving cognitive distortions with the "how I think" questionnaire. European Journal of Psychological Assessment, 24(3), 181-189. http://doi.org/10.1027/1015-5759.24.3.181

Oostermeijer, S., Nieuwenhuijzen, M., van de Ven, P. M., Popma, A., \& Jansen, L. M. C. (2016). Social information processing problems related to reactive and proactive aggression of adolescents in residential treatment. Personality and Individual Differences, 90, 54-60. http://doi.org/10.1016/j.paid.2015.10.035

Raine, A., Dodge, K., Loeber, R., Gatzke-kopp, L., Lynam, D., Stouthamer-loeber, M., \& Liu, J. (2006). The Reactive-Proactive Aggression Questionnaire: Differential Correlates of Reactive and Proactive Aggression in Adolescent Boys. Aggressive Behavior, 32(2), 159-171.

http://doi.org/10.1002/ab.20115.The

Smeets, K. C., Leeijen, A. A. M., van der Molen, M. J., Scheepers, F. E., Buitelaar, J. K., \& Rommelse, N. N. J. (2015). Treatment moderators of cognitive behavior therapy to reduce aggressive behavior: a metaanalysis. European Child \& Adolescent Psychiatry, 24(3), 255-64. http://doi.org/10.1007/s00787-014$0592-1$

Smeets, K. C., Oostermeijer, S., Lappenschaar, M., Cohn, M., van der Meer, J. M. J., Popma, A., ... Buitelaar, J. K. (2016). Are Proactive and Reactive Aggression Meaningful Distinctions in Adolescents? A Variable- and Person-Based Approach. Journal of Abnormal Child Psychology, 1-14. http://doi.org/10.1007/s10802-016-0149-5

Vitiello, B., \& Stoff, D. M. (1997). Subtypes of aggression and their relevance to child psychiatry. Journal of 
ROLE OF COGNITIVE DISTORTIONS IN AGGRESSION

the American Academy of Child and Adolescent Psychiatry, 36(3), 307-315.

http://doi.org/10.1097/00004583-199703000-00008

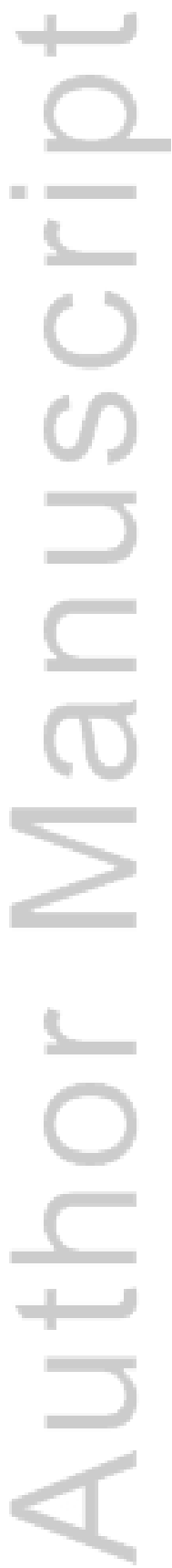

This article is protected by copyright. All rights reserved. 
6. Behavioral enactment

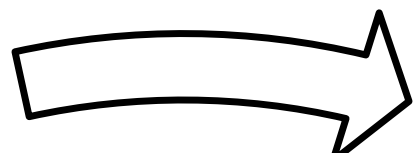

(个 RA 个PA)

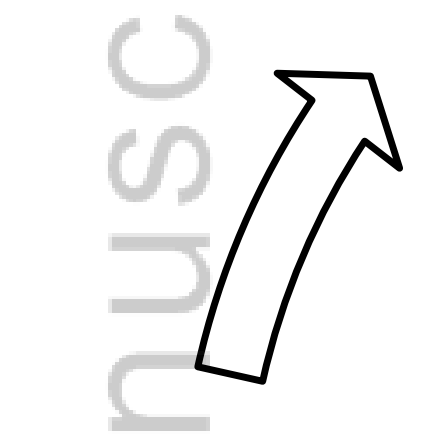

5. Response selection
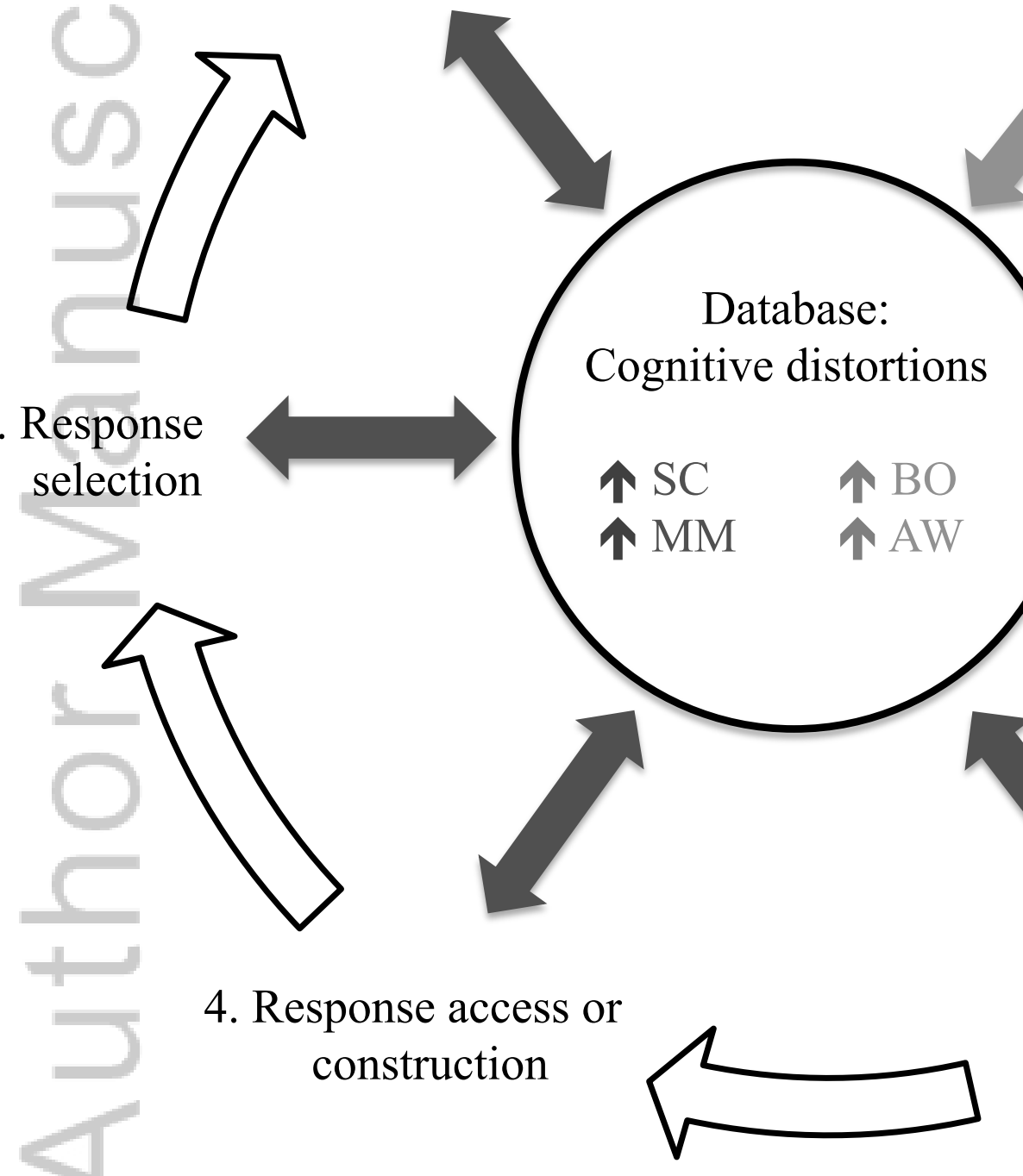

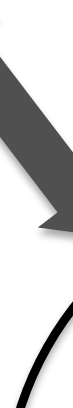
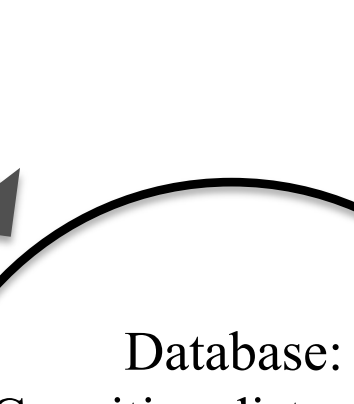

Cognitive distortions

1. Encoding of cues

3. Clarification

of goals

This article is protected by copyright. All rights reserved. 


\section{University Library}

\section{- M M I N E R VA \\ A gateway to Melbourne's research publications}

Minerva Access is the Institutional Repository of The University of Melbourne

Author/s:

Oostermeijer, S;Smeets, KC;Jansen, LMC;Jambroes, T;Rommelse, NNJ;Scheepers, FE;Buitelaar, JK;Popma, A

Title:

The role of self-serving cognitive distortions in reactive and proactive aggression

Date:

2017-12-01

Citation:

Oostermeijer, S., Smeets, K. C., Jansen, L. M. C., Jambroes, T., Rommelse, N. N. J., Scheepers, F. E., Buitelaar, J. K. \& Popma, A. (2017). The role of self-serving cognitive distortions in reactive and proactive aggression. CRIMINAL BEHAVIOUR AND MENTAL HEALTH, 27 (5), pp.395-408. https://doi.org/10.1002/cbm.2039.

Persistent Link:

http://hdl.handle.net/11343/292936 